\title{
SMART CITY GOVERNANCE FROM BELOW: HOW HUNGARIAN TOWNS RESPOND TO THE NEED FOR INSTITUTIONAL DESIGN AND DIGITAL CAPACITY BUILDING
}

\author{
Tamás Kaiser ${ }^{1}$
}

DOI: 10.24989/ocg.338.37

\begin{abstract}
One of the most important focal points of the complex processes taking place in the world has been created by highly diverse urbanisation zones, which all face similar problems. At the same time, for historical, economic and cultural geopolitical reasons, each town needs an approach that is tailored to its specific characteristics and needs. However, relatively little attention has been paid to developing the elements of a supportive environment, the process of planning and capacity-building needed to manage a smart city, and exploring concrete cases and best practices. This study examines initiatives supporting the conditions for smart city governance within the framework of the Digital Welfare Programme (DWP) launched in Hungary, with particular focus on the development of a marketplace as an info-communication platform to support the planning process.
\end{abstract}

\section{Introduction}

Today, around $55 \%$ of the world's population, over 3.5 billion people, lives in towns. This figure is expected to rise to $66 \%$ by 2050 , while the number and size of towns are also growing: while 83 towns had more than 1 million inhabitants in the 1950s, this number rose to 512 by 2016 [23]. The importance of urban areas is also demonstrated by the fact that the urban built environment accounts for only $3 \%$ of the world's total land, while it accounts for $60-80 \%$ of the world's energy consumption and $75 \%$ of its carbon dioxide emissions and use of natural resources [22]. As a major consequence of the above, twice as much energy will be needed by 2050, but at the same time, $\mathrm{CO}_{2}$ emissions should be cut by 50 percent to avoid dramatic climate change and its consequences. At the same time, besides general problems, it is evident - for historical, economic, cultural geopolitical reasons - that each town needs an approach that is tailored to its specific characteristics and needs. It is for this reason that the concept of a 'smart city' has recently received special attention. Although there is no uniform definition, it is interpreted in the extremely rich international and ever-growing domestic literature as the development and local application of innovative solutions, the efficient and sustainable use of towns' resources and cooperation with citizens. [12] [15].

So it is no exaggeration to claim that urban management has become one of the major development challenges of the $21^{\text {st }}$ century. So the smart city does not simply mean the introduction of digital technologies, but it also includes the development of a collaborative digital ecosystem based on the active involvement of stakeholders and citizens. The leading role of large towns is obvious, but small

\footnotetext{
${ }^{1}$ associate professor, University of Public Service, Department of Governance and Public Policy, H-1083Budapest 82 Üllöi Road, https://antk.uni-nke.hu, kaiser.tamas@uni-nke.hu
} 
and medium-sized towns have little or no resources, capacities and capabilities to address these challenges. Critical regional inequalities at both global and nation-state levels can be further exacerbated by varying degrees of digital maturity, the effects of which can be felt in economic, social and political dimensions [16] [18]. In order to address this problem, operation under changed conditions requires the introduction of new governance and management structures that are suited to the size and capabilities of towns, as well as the introduction of digital technologies. A growing body of literature on smart cities addresses different aspects of governance and management based on the mix of technology- and human driven approach [6] [9]. However, relatively little attention has been paid to developing the elements of a supportive environment, the process of planning and capacitybuilding needed to manage a smart city, and the exploration of concrete cases and best practices.

This paper seeks to examine the initiatives that support the conditions of smart city governance within the Digital Welfare Programme (DWP) launched in Hungary. The starting point is that smart city governance is a multi-level system that combines traditional institutional structures, stakeholder coordination platforms and elements of operational management. However, this is the result of longer institutional design and digital capacity-building, in which regional developmental differences, cultural factors and the extent of a 'digital gap' play a crucial role. The main aim of the paper is to outline the basis and directions for a forthcoming comprehensive research project. In this initial phase, the methods used include, in addition to an overview of the relevant literature, an analysis of DWP's regulatory environment, its strategic documents and pilot projects.

The paper is divided into three sections. First, based on an overview of the literature, we summarise the key elements of the smart city phenomenon, and in the second section, we examine the needs and capabilities needed to build a supportive environment for smart city governance. In the third section, we address the practical applicability of the theoretical model thus developed in one of the pilot programmes, and the creation of a marketplace implemented under the Digital Welfare Programme.

\section{The smart city as a phenomenon}

At present, smart city cannot be regarded as a theory or concept. However, there are many definitions, which can be grouped into three major types of smart city: some cities use smart technology (technology focus); others rely on smart people (human resources focus); yet others focus on smart collaboration (governance focus), or a combination of these three types, where appropriate [12]. Whichever definition we choose, the smart city is inextricably linked to economic, institutional, technological and cultural innovation taken in a broad sense.

Experience in practical implementation gained so far shows that the expansion of ICT-based technology and big data is a necessary but not a sufficient condition for a smart city to operate effectively, as there are many other factors and challenges that influence the life of urban communities, in addition to actually measurable values arising from economic development. For a town to be truly 'smart', its entire fabric needs to be explored, and the results need to be analysed, making it the subject of comprehensive social dialogue and discussion. In other words, in order for a town to attain digital transformation, it is first necessary to fully understand how it works and create a supportive environment for smart city operations.

Based on the above, the characteristics and measurability of a smart city are summarized below: 


\begin{tabular}{|l|l|}
\hline Dimensions & Measurable factors \\
\hline $\begin{array}{l}\text { Smart economy }- \\
\text { competitiveness }\end{array}$ & $\begin{array}{l}\text { innovative solutions, entrepreneurship, economic image and branding, } \\
\text { productivity, flexible labour market, international embeddedness, } \\
\text { smart specialization }\end{array}$ \\
\hline $\begin{array}{l}\text { Smart mobility }- \\
\text { transport and ICT } \\
\text { technology }\end{array}$ & $\begin{array}{l}\text { local accessibility, national and international accessibility, availability } \\
\text { of ICT-based infrastructure instruments, innovative and secure } \\
\text { transport systems }\end{array}$ \\
\hline $\begin{array}{l}\text { Smart Governance - } \\
\text { forms of participation }\end{array}$ & $\begin{array}{l}\text { multi-level institutional and management structure, citizen and } \\
\text { corporate participation, information transfer, developing forms of co- } \\
\text { design and co-creation based on a supportive environment }\end{array}$ \\
\hline $\begin{array}{l}\text { Smart environment - } \\
\text { natural resources }\end{array}$ & $\begin{array}{l}\text { attractive natural conditions, environmental protection, sustainable } \\
\text { resource management }\end{array}$ \\
\hline $\begin{array}{l}\text { Smart lifestyle }- \\
\text { quality of life }\end{array}$ & $\begin{array}{l}\text { cultural institutions, health conditions, individual safety, housing } \\
\text { quality, educational institutions, tourist attractions, social cohesion }\end{array}$ \\
\hline $\begin{array}{l}\text { Smart people - social } \\
\text { and human capital }\end{array}$ & $\begin{array}{l}\text { level of education, willingness for lifelong learning, social and ethnic } \\
\text { pluralism, flexibility, creativity, openness, engagement in public life }\end{array}$ \\
\hline
\end{tabular}

Table 1: Exploring the nature of smart cities

Source: Own contribution with additions based on GIFFINGER et al. 2007 [8]

This is, of course, a very comprehensive overview, in which categories can be quantitatively measured and evaluated using various variables, but each factor can also provide a basis for qualitative research [4]. In what follows, we examine the background and potential elements of building a supportive environment from the dimension of smart governance focusing particularly on the emerging role of platforms, business models and market places as elements of participation and active contribution.

\section{Prerequisites for smart governance: developing a supportive environment}

In recent years, cities have become 'smart' not only in the sense that they are now able to automate routine functions that serve, on the one hand, individuals, buildings and transport systems, and, on the other hand, provide opportunities for monitoring, analysing, and ultimately understanding and planning the everyday lives of cities. In any case, the experience gained so far has shown that there are no 'one-size-fits-all' solutions for 'becoming smart', and that pioneering cities have largely adopted strategies and action plans that are tailored to their own situations and capabilities [10] [17]. In addition to this diversity, however, three principles can be identified as the key pillars for building a supportive environment: an integrated approach to economic development and public service planning, creating the conditions for the practical, feasible and financially sound selection of investment projects, and ensuring the participation and active contribution of stakeholders (private sector, citizens, academics, government).

This requires also a 'digital elite' (entrepreneurs, managers, media professionals), whose attraction and retention is one of the most important tasks. However, the success of becoming a real smart environment depends on a dynamic and stimulating culture that active participation and commitment of the people can be created, along with the development of a sense of 'ownership' in regard to joint planning and development projects. This also means that, in practice, a smart city is based on the network of actors involved and the cooperation among stakeholders based on mutual benefits [11] [14]. 
This highly complex system is subdivided into further thematic units, such as infrastructure, energy, transport, water management, services and building management, which have their own communication systems, data, platforms and applications, but in separate organizational structures (silos), limiting access to data and their use. Today, a vast amount of data can only meet specific needs, but are essentially lost for common good. Therefore, linking different standards and integrating them into complex info-communication platforms are an essential element of moving forward [2] [3].

The platform relies on the basic infrastructure available, but constantly upgrades it with state-of-theart technology to match demand and supply, such as the quick and easy collection and delivery of publicly available spatial data, area codes, demographic, tourism and economic data. The platforms take advantage of opportunities provided by the town, while requiring the least amount of investment from the service provider. The common basis for this is reconsideration of urban governance, creating new forms of institutional and partnership agreement based on digitalisation, management techniques and the necessary human capacity. In addition, new instruments supporting design and decisionmaking are needed to build a business model that can be applied across the public sector by showing how to create and capture value [13] [19]. Business models provide a tool for stimulation and testing the innovative ideas as well as serve as an appropriate tool to explore and understand the role, attitude and motivation of different stakeholders at territorial and urban level [1] [20] [21].

Building a business model, a marketplace, is one of the most important instruments for planning and management in the development of smart cities. The marketplace is an open info-communication platform that connects government actors and investors with vendors of new technologies. The platform will help towns find comparable information on products, validated results of previous investments and peer reviews. As for vendors, they can offer their products and related smart solutions, as well as showcase their previously successful innovations, focusing on types of towns and technologies. The key function of the smart city marketplace is therefore to facilitate, as well as simplify and accelerate, the process of matching supply and demand, and to confirm and validate new technologies and the conditions for their application. An important element of the viability and sustainability of the marketplace is the spill-over effect, as a result of which new cities, data, information and feedback are constantly added.

The European Innovation Partnership on Smart Cities and Communities (EIP-SCC), which aims to bring together cities, industrial companies, small and medium-sized enterprises, banks, researchers and all stakeholders involved in smart city investments, is crucial among European examples [7]. The EIP-SCC is actually an information and communication hub, which is used to communicate the latest news, events, documents, partnerships and development results. The platform makes it possible to find partners with appropriate expertise and experience in joint development projects, provides insight into completed or ongoing projects, evaluates the obstacles and opportunities arising during implementation, and benefits from inspirational results. Similarly, the platform can be used to present and promote a particular project and enhance its visibility, thus attracting new investors. Last but not least, EIP-SCC assists in exploring funding opportunities and information on current EU grant opportunities.

EIP-SCC also acts as a forum for discussion. It is suitable for initiating a dialogue on a specific issue, discussing the best ways to overcome obstacles and achieve results. It engages public and private actors and stakeholders in a discourse on smart city development across Europe. One of the initiatives ids the EIP-SCC's action cluster on Business Models, Financing and Procurement for Smart Cities (AC BM), lead by the EUROCITIES, a city network of over 140 European cities. The AC BM organizes expert-level discussions has proved to be an ongoing platform to promote and share ideas. 
Another key initiative is the Matchmaking activity which supports city project promoters with financing by bringing smart city projects closer to investors with the aim of developing better quality projects from the viewpoint of financing.

Marketplace-type planning instruments are already available in several countries, allowing for flexible adaptation to local needs and opportunities and taking into account the particular level and spatial distribution of digital maturity. In the next section, we will present a marketplace toolkit within the DWP launched by the Hungarian government in 2017 that focuses on the needs and opportunities of small and medium-sized towns.

\section{The marketplace as an open platform and digital stimulus: an opportunity for small and medium-sized towns in Hungary}

In 2015, the Hungarian Government began a comprehensive digital development strategy with DWP 1.0. In the first phase, measures were introduced into the public administration system (e.g. free WiFi in town centres and creation of a public data cadastre). ${ }^{2}$ The second phase, which began in 2017 (DWP 2.0), defined the areas of development by chapter and coordinated implementation within the governmental organisation ${ }^{3}$ Currently the implementation of the strategy has been managed by the Ministry of Innovation and Technology - with interdepartmental competence ${ }^{4}$. 'DWP Points' $(1,500$ in place at the end of 2019) assist smart city projects throughout the country, though mainly in smaller settlements. They are designed to provide scope for digital literacy development and electronic administration. These specific tasks are aided by a 100-person mentoring network.

The four pillars of the DWP are digital infrastructure, digital competencies, the digital state and the creation of a digital economy. The pillars are supported by horizontal themes, and in this area we find the smart city development fields fall into three interrelated subfields. The three subfields are as follows: professional training in digital regional development, smart city pilot programmes and a smart city marketplace. According to Article 3 of Government Decree 56/2017 (III.20.), cited above, a "Smart city means a city (or town) that develops and implements its integrated urban development strategy on the basis of a smart city methodology, a town or group of towns that develops its natural and built environment, its digital infrastructure and the quality and economic efficiency of its services using modern and innovative information technologies in a sustainable manner, with the increased involvement of the population." The horizontal nature of smart city development is also reflected in the fact that its implementation is supported by the main pillars. The digital state in and of itself entails the digital renovation of public administration, including the support of the online presence of local governments and the creation of a level playing field for the Hungarian digital industry. The digital competencies pillar encompasses Hungary's digital education strategy and digital competency development. Among other things, the digital economy pillar contains Hungary's digital start-up strategy.

In order to reach the scale and scope of the emerging supportive environment, Government Decree No. 252/2018 (XII. 17.) on the Establishment and Operation of Smart City Central Platform Services appointed the Lechner Knowledge Centre as the provider of the centralised public service of the Geographic Information System Platform for Settlements and designated the city of Monor as the local government that is currently connected to the smart city central platform service; subsequently,

\footnotetext{
${ }^{2}$ See: Government Decree 2012/2015 (XII.19.) DWP 1.0

${ }^{3}$ See: Government Decree 1456/2017 (VII.19.) DWP 2.0

${ }^{4}$ See: Government Decree 94/2018 (V.22.)
} 
other cities will follow suit. The essence of the platform is that a central "standard package" will be developed, open for other settlements to join, and they will need to deal only with those developments that serve specific local needs. In addition the Lechner Knowledge Centre develops Smart City Methodologies. Based on the requirements of Hungarian cities and the guidance of the European Union, the methodologies contain proposals that may ensure the systemic implementation of certain smart city development models. The Inventory of the Smart City Methodologies already contains 234 projects in Hungary, and 900 in the world in total. In Hungary, it monitors projects implementing smart city developments in roughly 66 settlements $^{5}$.

From 2017 onwards, the marketplace element of the smart city component of the DWP strategy has been constantly evolving as a complex software solution - in a form of an info-communication platform - for developers and suppliers to present their smart city products and buyers to learn about the detailed features of the products. The platform established contains legally, technically and economically validated and quality-assured suppliers and products and makes them available primarily to local governments, state and municipal institutions and business associations. One of the most important aspects of the marketplace is that the services provide financing options and return calculations, which greatly facilitate the work of municipal decision-makers considering smart urban developments. The goal is to make it easier for customers involved in the development (city leaders, company representatives) to find the right tools to meet their needs.

The process of entering the platform begins after registration with the creation of a profile. This is important in order for the platform to categorise settlements based on size and economic, social, geographical characteristics and issue maps. Registration and access to information is free for municipalities, while businesses have to pay a minimal fee. They will then have access to the marketplace, including the product catalogue. The most important element of the latter is a datasheet of available products, which contains legal and warranty information, technical and compatibility data, investment costs, and social impact figures. A similar process takes place on the vendor side of the marketplace. After registration, candidates enter into a contract with the marketplace, followed by legal, technical and economic validation, then a social return calculation. This process results in a product data sheet which is made available to customers. The marketplace offers other services in the existing product catalogue, including trademarks, the registration of consultants, newsletters and blog information on financing options, and. in this context, runs a return calculator [5]

The functioning of the marketplace is closely linked to the other two elements of the horizontal theme of the DWP smart city. Specialist training in digital spatial development, the first comprehensive smart graduate training course in Hungary, is provided by the Edutus University, the National University of Public Service and the Moholy-Nagy University of Art and Design. The target group is made up of professionals who have the appropriate knowledge and influence on the decision-making processes of their cities or towns. The aim is to train professionals who have a thorough knowledge of the relationship between digitisation and towns and cities and smart city considerations and practices. Graduates will be aware of smart city solutions and will have enough knowledge to launch and implement a related project.

The second component, the first phase of pilot projects at nine sites, is undergoing substantive studies. ${ }^{6}$ The methodology applied during the studies can serve as an example for municipal (smart

\footnotetext{
${ }^{5}$ See in detail: Smart City Methodologies, available at: http://okosvaros.lechnerkozpont.hu/hu

6 The pilot project locations: three districts in Budapest (the 8th, 11th and 17th), Tata and Tata County districts, Balatonfüred and Balatonfüred County districts, Tamás, Nyíradony and Nyíradony County districts, and two non-urban
} 
city) developments: it plans data-based developments, takes into account the size and needs of the user community, the aspects of financing and sustainability, and the characteristics of the settlement. It is significant that the methodology also utilises the results of other digital strategies (e.g. education strategy, agricultural strategy, health strategy, Carpathian Basin digital ecosystem) applied to the situation assessment of smaller settlements. Finally, the studies present the cost structure (investment and maintenance) of the proposed improvements based on the identified capabilities and opportunities, as well as the calculation of the return on the improvements.

The tools of this methodology are opinion polls and the secondary data collection (examination of the administrative, economic, IT and social characteristics of the settlement/region based on the data of the Hungarian Central Statistical Office), the enumeration of existing developments, their analysis, the processing of accepted site development plans, and interviews with decision makers, the civil sector and institutional leaders, i.e. all stakeholders in the area. The main purpose of surveys is to assess the digital status of a given area. The main elements of these surveys is to explore sociodemographic and statistical issues, use of internet and social media, use of e-government (customer gateway, e-administration), commerce, and use of electronic payment methods and smart tools. [5]

It is too early to assess the effectiveness of the DWP marketplace. At the same time, it can be seen that in the realisation of smart city governance, the goals and tools of a supportive environment based on a common logic, and a multi-level, layered institutional structure are beginning to emerge.

\section{Conclusions}

According to some estimates, the number of connected devices, commonly known as the IoT (Internet of Things), could reach 50 billion by 2020. In the urban environment, new technologies appearing on the market are making significant changes to the life and functioning of cities. Experience has shown that all forms of settlement have to respond to rapid changes, so becoming a smart city could be understood as an inevitable process. However, this is not a development based on straightforward and unified models. Developments must take into account the geographical location, aptitude, level of development and size of the city. In many respects, the problems of small and medium-sized towns are different from those of developed large towns. Here, a lack of financial resources, difficulties in public procurement, and restrictions on the use of ICT tools are serious obstacles. This does not mean, of course, that a small town cannot be a smart city in general but it is particularly important at this early stage to introduce smaller-scale developments that can be directly felt in everyday life, such as smart parking, street lighting and waste management.

However, the use of ICT tools, platforms and the marketplace as an open info-communication platform is not enough to build a smart city. The creation and operation of the supportive environment - especially the marketplace - is often a long-awaited solution: the market for smart city applications and products is not regulated, there is no monitoring system for technical, economic and social features and impacts of the investments implemented under the title of smart city) and these circumstances may hinder the realisation of the developments at settlement and regional level.

The experiences of the initial phase of the implementation of the digital development strategy in Hungary clearly indicates that there is a strong need to create a supportive environment which requires the full involvement and cooperation of the municipal government and the citizens, as well as the

development areas: Tokaj, the mountain range, which covers the area of the Tokaj wine region, and the heart of Pannonia, which covers part of Lake Velence and the Vértes Mountains. 
development of effective management structures, business models, platforms and a sustainable marketplace. These efforts follow the good practices developed elsewhere, but showcase mainly Hungarian solutions, providing a space for Hungarian small and medium size towns and enterprises to present themselves and their innovative solutions.

Yet in order to unravel the details, a great deal of research is still needed, particularly in the areas of management, governance, technology, public policy, urban communities, the economy, built infrastructure and the natural environment. These factors form the basis of an integrative framework capable of exploring the processes that determine the future of a smart city. However, within this overall framework, our future research must pay particular attention to the different dimensions of governance, where city leadership plays an important role not only in producing smart city content, but also in understanding and managing the smart city operation.

\section{References}

[1] ANTHOUPOUlOS, L., FITSILIS, P. and ZIOZIAS, C., What is the Source of Smart City Value?: A Business Model Analysis. International Journal of Electronic Government Research, Volume 12, Issue 2, April, 56-76., 2016

[2] ANTTIROIKO, A-V., City-as-a-Platform: Towards citizen-centred platform governance. Paper prepared for the RSA Winter Conference 2016 on New Pressures on Cities and Regions, 24-25 November 2016, London, UK, available at: https://www.regionalstudies.org/wpcontent/uploads/2018/07/Anttiroiko_Ari-Veikko___City-as-a-Platform.pdf Downloaded: 20 February 2020

[3] BARNES, S., Smart cities and urban data platforms: Designing interfaces for smart governance, City, Culture and Society, Volume 12, March, 5-12. 2018

[4] CAIRD, S., City approach to smart city evaluation and reporting case studies in the United Kingdom. Urban Research \& Practice, June, Volume 11, 159-180. 2018.

[5] DigitÁliS JÓlÉT NONPROFIT KFT (ed.), Civitas Sapiens 2020 Smart City Conference. Conference Proceeding, Budapest, National University of Public Service, 19 September 2020, 9-10, 2020

[6] DYER, M., GLEESON, D. and GREY, T., Framework for Collaborative Urbanism, in: CERTOMÁ, C., DYER, M., POCATILU, L., and RIZZI, F. (eds). Citizen Empowerment and Innovation in the Data-Rich City. Tracts in Civil Engineering. Cham: Springer, 19-30. 2017

[7] EUROPEAN INNOVATION PARTNERSHIP ON SMART CITIEs AND COMMUNITIES, Marketplace of the European Innovation Partnership on Smart Cities and Communities. Towards a Joint Investment Programme of European Smart Cities. A Consulation Paper to Stimulate Action. 2018. Available:: https://eu-smartcities.eu/sites/default/files/2018-06/EIPSCC_TOWARDS\%20A\%20JOINT\%20INVESTMENT-Paper.pdf Downloaded 20 February 2020

[8] GIFFINGER, R., FERTNER, C., KRAMAR, H. and MEIJERS, E., City-ranking of European Medium-Sized Cities, 2007. Available: http://www.smart-cities.eu/download/city_ranking final.pdf Downloaded: 20 February 2020 
[9] HOLLANDS, R. G., (2015). Critical Interventions into the Corporate Smart City. Cambridge Journal of Regions, Economy and Society, 8 (1): 61-77. 2015

[10] KITCHIN, R., LAURIAULT, T. P. and McARDLE, G., Data and the city, Routledge, 2018

[11] LELEUX, Ch. and WEBSTER, W., Delivering Smart Governance in a Future City: The Case of Glasgow. Media and Communication, Volume 6, Issue 4, 163-164. 2018

[12] MEIJER, A. and BOLÍVAR, M. P. R., Governing the smart city: a review of the literature on smart urban governance. International Review of Administrative Sciences, Vol. 82, 392-408. 2016

[13] OSTERWALDER, A. and PIGNEUR, Y., (2010), Business Model Generation: A Handbook For Visionaries, Game Changers, And Challengers, New York, Wiley 2010

[14] PEREIRA, G., CUNHA, M. A., LAMPOLTSHAMMER, T. J., PARYCEK, P. and TESTA, M. G., Increasing collaboration and participation in smart city governance: a cross-case analysis of smart city initiatives. Information Technology for Development, 23:3, 526-553. 2017

[15] PEREIRA, V. G., PRYCEK, P., FALCO, E. and KLEINHANS, R., Smart Governance in the Context of Smart Cities: A Literature Review. Information Polity, forthcoming, available: https://www.researchgate.net/publication/325304603_Smart_governance_in_the_context_of_ smart_cities_A_literature_review Downloaded: 20 February 2020

[16] RODRIGUEZ-POSE, A., The revenge of the places that don't matter (and what to do about it). Cambridge Journal of Regions, Economy and Society. Volume 11, Issue 1, 10 March 2018, 189-209.

[17] SANCINO, A. and HUDSON, L., Leadership in, of, and for smart cities - case studies from Europe, America, and Australia. Public Management Review, 2020, DOI: 10.1080/14719037.2020.1718189 Downloaded: 20 February 2020

[18] STORPER, M., Separate Worlds? Explaining the current wave of regional economic polarization. Journal of Economic Geography. Volume 18, Issue 5, 247-270. 2018

[19] ShETTY, N., RENUKAPPA, S., SURESH, S. and ALGAHTANI, K., Smart city business models -A systematic literature review. 3rd International Conference on Smart Grid and Smart Cities 2019, June 25-28, 2019 | University of California, Berkeley, USA

[20 ] SHETTY, N., RENUKAPPA, S. and SURESH, S., Innovative Business Models for Smart Cities - A Systematic Research. International Journal of Innovative Technology and Exploring Engineering, Volume8 Issue 128, October 2019

[21] TIMEUS, K., VINAIXA, J. and PARDO-BOSCH, F., Creating business models for smart cities: a practical framework. Public Management Review, 2020 DOI: 10.1080/14719037 .2020.1718187 Downloaded: 20 February 2020

[22] UNITED NATIONS ENVIRONMENT PROGRAMME, City-Level Decoupling: Urban resource flows and the governance of infrastructure transitions. A Report of the Working Group 
on Cities of the International Resource Panel. Swilling M., Robinson B., Marvin S. and Hodson M, 2013.

[23] UNITED NATIONS, World Urbanization Prospects: The 2014 Revision, Available: https://esa.un.org/unpd/wup/Publications/Files/WUP2014Report.pdf. Downloaded: 20 February 2020. 